\title{
Influencing biophysical properties of fibrin with buffer solutions
}

\author{
Esther Potier · Jérôme Noailly • \\ Christoph M. Sprecher · Keita Ito
}

Received: 2 November 2009/Accepted: 9 January 2010/Published online: 26 January 2010

(c) The Author(s) 2010. This article is published with open access at Springerlink.com

\begin{abstract}
Fibrin has been proposed as cell scaffold for numerous tissue engineering applications. While most of the studies have focused on fibrinogen and thrombin, other components of fibrin can also affect its properties. The present study aimed to evaluate the effects of buffer solution composition on fibrin biophysical properties. Fibrin scaffolds were synthesized with different calcium, chloride, and factor XIII (FXIII) final concentrations. Light transmission was determined as a relative, semi-quantitative estimator of fiber structure differences, and two compositions, resulting in translucent and opaque gels, were tested for mechanical and biological properties. Gels were seeded with mouse mesenchymal cells, C3H10T1/2, or bovine bone marrow-derived mesenchymal stromal cells and cultured up to 10 or 24 days, before cell number, morphology and distribution were evaluated. Calcium increased gel opacity (i.e., fiber thickness), while chloride and FXIII decreased it. Opaque gels displayed a fluid-like viscous behavior while translucent gels showed improved elastic properties. Both compositions supported survival of both cell types with opaque gels leading to better proliferation, but significant scaffold shrinkage after 17 days of culture. These results demonstrated that calcium, chloride, and FXIII modulate the biophysical properties of fibrin,
\end{abstract}

E. Potier $\cdot$ J. Noailly $\cdot$ C. M. Sprecher

AO Research Institute, Clavadelerstrasse 8, 7270 Davos,

Switzerland

E. Potier $(\bowtie) \cdot J$. Noailly $\cdot$ K. Ito

Department of Biomedical Engineering, Eindhoven University

of Technology, P.O. Box 513, 5600 MB Eindhoven,

The Netherlands

e-mail: e.potier@tue.nl; esther.potier@gmail.com and can be used to adjust mechanical and biological properties for tissue engineering applications.

\section{Introduction}

Fibrin glues are biological hydrogels reproducing the final stages of the clotting cascade: the conversion of the soluble plasma fibrinogen into insoluble fibrin by the action of thrombin [1]. Since many years, fibrin glues have been widely used as surgical sealants. More recently, they also have been proposed as scaffolding for cell delivery in several tissue engineering applications [2]. Numerous in vitro studies, indeed, have demonstrated the ability of fibrin gels to support survival, proliferation, and/or differentiation of many cell types [3-6], including mesenchymal stromal cells (MSCs) [7-9].

This aptitude to sustain cell growth is regulated, in part, by the fibrin gel composition. Fibrin glues usually consist of two constituents: highly concentrated fibrinogen and thrombin [10]. The fibrinogen buffer solution also includes factor XIII (FXIII), anti-fibrinolytic agent (aprotinin or tranexamic acid), fibronectin, and traces of other plasma proteins, such as plasminogen. Thrombin buffer solution, on the other hand, contains calcium and sodium chlorides. High fibrinogen, and to a lesser extent low thrombin, concentrations have been shown to reduce the proliferation of human MSCs [7-9] and dermal fibroblasts [3]. The fibrinogen concentration thresholds determined by these studies, however, varied from 18 to $50 \mathrm{mg} / \mathrm{mL}$ fibrinogen. This high variability in cell behavior in response to fibrinogen concentrations might be explained by other components of the fibrin gel whose concentrations were not considered, but are known to affect gel properties, potentially affecting cell behavior. Calcium and chloride 
contained in the thrombin component, for example, are both known to influence fiber thickness and gel porosity [11-13]. FXIII, on the other hand, can affect mechanical properties [14] and cell behavior, as high concentrations inhibited process extension of human umbilical vein endothelial cells [15].

The objective of the present study was to modulate the mechanical and biological properties of fibrin keeping fibrinogen and thrombin constant. To do so, thrombin was diluted in buffers containing different calcium, chloride, and FXIII concentrations. The relative structure of the resulting hydrogels was then estimated by light transmission measurements as it has been demonstrated that opacity of fibrin is directly related to its structure (fiber mass/length ratio) [16]. Two buffer compositions, leading to opaque (thick fibers, large pores $[12,16,17])$ and translucent (thin fibers, narrow pores $[12,16,17])$ gels, were then selected. For these gels, mechanical properties were assessed by relaxation tests, and biological properties were tested with short- and long-term cell cultures. For short-term experiments, both scaffolds were seeded either with mouse mesenchymal cell line C3H10T1/2 or with primary bovine bone marrow-derived MSCs (BMSCs) and cultured up to 10 days. At this time, cell number, morphology and distribution were evaluated. For long-term experiments, both translucent and opaque gels were seeded with BMSCs and cultured up to 17 and 24 days. Cell morphology and distribution were then determined.

\section{Materials and methods}

Fibrin gel synthesis

The fibrinogen $(\mathrm{Fb})$ component was reconstituted in aprotinin solution and diluted from 90 to $25 \mathrm{mg} / \mathrm{mL} \mathrm{Fb}$ in fibrinogen diluent buffer. The thrombin (Thr) component was reconstituted in $\mathrm{CaCl}_{2}$ solution and diluted from 500 to 62.5 U/mL Thr in diluent buffers containing different concentrations of $\mathrm{CaCl}_{2}, \mathrm{NaCl}$ (both Sigma; Buchs, Switzerland) and factor XIII (FXIII) to produce gels containing different calcium, chloride, and FXIII final concentrations (Table 1). All gels contained $20 \mathrm{mg} / \mathrm{mL}$ of fibrinogen and $14 \mathrm{U} / \mathrm{mL}$ of thrombin. Buffer $\mathrm{pH}$ and concentrations of all other components known to be in the reconstitutive and diluent solutions (aprotinin, human serum albumin (HSA), fibronectin, $\mathrm{Na}_{3}$ citrat, niacin amid, and histidin) were adjusted and kept constant in all compositions. Components of Tisseel VH S/D (fibrinogen, thrombin, fibrinogen diluent buffer, aprotinin, $\mathrm{CaCl}_{2}$, FXIII, and HSA solutions) were kindly provided by Baxter Innovations $\mathrm{GmbH}$ (Vienna, Austria).

For light transmission measurements and cell culture experiments, $50 \mu \mathrm{L}$ of Thr solution was transferred into a custom made mold $(\varnothing 8 \times 4 \mathrm{~mm})$ and $180 \mu \mathrm{L}$ of Fb solution was added and mixed pipetting up and down several times. Gels were incubated 10 min at RT before covering them with phosphate buffered saline (PBS) to avoid fibrin

Table 1 Fibrin composition

\begin{tabular}{|c|c|c|c|c|c|c|}
\hline & $\begin{array}{l}\text { Composition } \\
\text { Fb.Thr.Cl.Ca.FXIII }\end{array}$ & $\begin{array}{l}\text { Fibrinogen } \\
(\mathrm{mg} / \mathrm{mL})\end{array}$ & $\begin{array}{l}\text { Thrombin } \\
(\mathrm{U} / \mathrm{mL})\end{array}$ & $\begin{array}{l}\mathrm{Ca}^{2+} \\
(\mathrm{mM})\end{array}$ & $\begin{array}{l}\mathrm{Cl}^{-} \\
(\mathrm{mM})\end{array}$ & $\begin{array}{l}\text { FXIII }^{\mathrm{a}} \\
(\mathrm{U} / \mathrm{mL})\end{array}$ \\
\hline \multirow[t]{9}{*}{$\mathrm{Ca}^{2+} /$ FXIII effects } & 20.14.2.36.6 & 20 & 14 & 2 & 36 & 6 \\
\hline & 20.14.2.36.12 & 20 & 14 & 2 & 36 & 12 \\
\hline & 20.14.2.36.18 & 20 & 14 & 2 & 36 & 18 \\
\hline & 20.14.9.36.6 & 20 & 14 & 9 & 36 & 6 \\
\hline & 20.14.9.36.12 & 20 & 14 & 9 & 36 & 12 \\
\hline & 20.14.9.36.18 & 20 & 14 & 9 & 36 & 18 \\
\hline & 20.14.15.36.6 & 20 & 14 & 15 & 36 & 6 \\
\hline & 20.14 .15 .36 .12 & 20 & 14 & 15 & 36 & 12 \\
\hline & 20.14 .15 .36 .18 & 20 & 14 & 15 & 36 & 18 \\
\hline \multirow[t]{6}{*}{$\mathrm{Cl}^{-} / \mathrm{FXIII}$ effects } & 20.14.2.36.12 & 20 & 14 & 2 & 36 & 12 \\
\hline & 20.14.2.36.18 & 20 & 14 & 2 & 36 & 18 \\
\hline & 20.14.2.100.12 & 20 & 14 & 2 & 100 & 12 \\
\hline & 20.14.2.100.18 & 20 & 14 & 2 & 100 & 18 \\
\hline & 20.14 .2 .200 .12 & 20 & 14 & 2 & 200 & 12 \\
\hline & 20.14.2.200.18 & 20 & 14 & 2 & 200 & 18 \\
\hline
\end{tabular}

Fibrinogen $(\mathrm{Fb})$, thrombin $(\mathrm{Thr})$, chloride ion $\left(\mathrm{Cl}^{-}\right)$, calcium ion $\left(\mathrm{Ca}^{2+}\right)$, and factor XIII (FXIII) final concentrations in fibrin scaffolds. Italicized compositions were tested for mechanical and biological properties. All other known components were kept at constant concentrations. Concentrations were calculated taking all sources (fibrinogen and thrombin stock solutions and buffers) into account

${ }^{a}$ As FXIIIa (FXIII activated by calcium) is known to be unstable, the FXIII concentrations indicated here might not be representative of the final FXIIIa concentrations 
dilution with PBS. Gels were further incubated $30 \mathrm{~min}$ at RT to achieve polymerization. The gels produced proved to be homogenous, as observed with the light transmission measurements (pictures not shown). For mechanical testing, $275 \mu \mathrm{L}$ of Thr solution was transferred into a custom made mold $(\varnothing 16 \times 5.5 \mathrm{~mm})$ and $990 \mu \mathrm{L}$ of $\mathrm{Fb}$ solution was added and mixed. Gels were incubated $10 \mathrm{~min}$ at RT, covered with PBS and further incubated $60 \mathrm{~min}$ at RT. For mechanical characterization, gels were kept between $24 \mathrm{~h}$ and $48 \mathrm{~h}$ at $4{ }^{\circ} \mathrm{C}$ in PBS before testing.

\section{Light transmission measurements}

Gels were placed in a Petri dish filled with PBS and were diffusely illuminated with a Kaiser light plate. Pictures of the gels were taken with the Macrofluo ${ }^{\text {TM }}$ macroscope (Leica Microsystems; Heerbrugg, Switzerland) and an AxioCam HR camera supported by the Axiovision software (both Carl Zeiss; Feldbach, Switzerland). Light transmission was then measured as gray levels in a $6.6 \mathrm{~mm}$ diameter circle centered on the gel (to avoid border effects/ artefacts) using Axiovision imaging software (Version 4.4), with high turbidity corresponding to low transmission values and low turbidity to high transmission values. Results are expressed relative to the 20.14.2.36.18 composition (corresponding, respectively, to $20 \mathrm{mg} / \mathrm{mL}$ fibrinogen, $14 \mathrm{U} / \mathrm{mL}$ Thrombin, $2 \mathrm{mM} \mathrm{Ca}^{2+}, 36 \mathrm{mM} \mathrm{Cl}^{-}$, $18 \mathrm{U} / \mathrm{mL}$ FXIII; common to the two sets of experiments determining the effects of calcium/FXIII and chloride/ FXIII). The reproducibility of the method used here was insured by repetitive measurements of the relative differences between gray values returned by five polymer plates of different translucence/opacities.

\section{Mechanical characterization}

Six gels of each selected composition (20.14.2.200.12 and 20.14.15.36.6) were placed in PBS at $37{ }^{\circ} \mathrm{C}$ and compressed between two flat electro-polished stainless steel top and bottom plates. Experiments were driven using a Bose ELF 3220 (Bose Corporation; ElectroForce System Group, Minnesota, USA) equipped with a Burster 8432-2.5 N precision mini force cell in line with a Burster 9243 high resolution amplifier (both Burster; Gernsbach, Germany). The upper plate was first lowered under quasi-static conditions $(0.0002 \mathrm{~mm} / \mathrm{s})$ until full contact with the top surface of the sample was achieved. Distance between samples and top plate was visually assessed with the Axiocam HR camera supported by the Axiovision software. Once full contact was achieved, specimens were allowed to relax completely, and the piston position was taken as $0 \%$ strain. Three quasi-static loading-unloading preconditioning cycles were driven between 0 and $2 \%$ compressive strain.
Two percent of compressive strain steps were then successively applied from 0 to $10 \%$, with loading ramps at $0.1 \mathrm{~mm} / \mathrm{s}$. Each load step was followed by a complete relaxation period. This relaxation period was selected for each gel composition as the time required to achieve full relaxation. Samples under full contact with the piston were quickly loaded at $0.1 \mathrm{~mm} / \mathrm{s}$ up to $2 \%$ compressive strain and full relaxation was assumed when the monitored reaction force reached a plateau, stable for a minimum time period of $10 \mathrm{~min}$. During the multi-step stress relaxation experiment, reaction forces and actual displacement timed data were recorded. For each gel formulation $(n=6)$, these data were averaged and used to assess particular physical parameters, representative of the fibrin poroviscoelastic behavior. Equilibrium elastic stiffness $(E)$, hydraulic permeability $(\kappa)$, viscoelastic relaxation time $(\lambda)$, and viscoelastic shear modulus $\left(G_{\mathrm{v}}\right)$ values were then theoretically estimated at $4 \%$ strain, according to a previously reported method [18].

\section{Cell culture}

C3H10T1/2 (American Type Cell Collection; Molsheim, France) were cultured with Basal medium Eagle (BME; Sigma) containing $10 \%$ fetal bovine serum (FBS), $20 \mathrm{mM}$ Hepes, and $1 \%$ antibiotic/antimycotic solution (all Gibco; Basel, Switzerland). Bovine BMSCs were isolated from three calves (3- to 5-month-old) in accordance with local regulations. Bone marrow was aspirated from the pelvises and immediately mixed with heparin (5,000 UI; Fresenius Medical Care; Stans, Switzerland). Bone marrow samples were then washed with Tyrode's balanced salt solution (TBSS), centrifuged and seeded in Alpha minimum essential medium ( $\alpha$ MEM; Gibco) containing 10\% FBS, $20 \mathrm{mM}$ Hepes, and $1 \%$ antibiotic/antimycotic solution. When reaching $80 \%$ of confluence, cells were detached, resuspended in $90 \%$ FBS $/ 10 \%$ dimethylsulfoxide (Sigma), and stored in liquid nitrogen. A fresh batch of BMSCs was thawed and cultured for each experiment (each passage at 5,000 cells $/ \mathrm{cm}^{2}$ ). Cells from each donor were cultured separately.

\section{Cell seeded gels}

C3H10T1/2 (passage 8) and bovine BMSCs (passages 3-5) were detached. For BMSCs, the three donors were pooled with a ratio of $1 / 3$ for each donor. Cells were centrifuged and re-suspended in $\mathrm{Fb}$ solution $(25 \mathrm{mg} / \mathrm{mL} \mathrm{Fb})$ at $8 \times 10^{5}$ cells $/ \mathrm{mL}$. Thr and $\mathrm{Fb} / \mathrm{cell}$ solutions were then mixed to produce fibrin scaffolds $(230 \mu \mathrm{L})$ as indicated before in fibrin gel synthesis (final concentration of $6.26 \times 10^{5}$ cells $/ \mathrm{mL}$, corresponding to $1.44 \times 10^{5}$ cells/ scaffold). Carriers seeded with C3H10T1/2 were cultured for 7 and 10 days in BME containing 5\% FBS, $500 \mathrm{KIU} / \mathrm{mL}$ 
aprotinin (Sigma), $20 \mathrm{mM}$ Hepes, and 1\% antibiotic/antimycotic solution. Carriers seeded with bovine BMSCs were cultured for $7,10,14,17,21$, and 24 days in $\alpha \mathrm{MEM}$ containing 5\% FBS, $500 \mathrm{KIU} / \mathrm{mL}$ aprotinin, $20 \mathrm{mM}$ Hepes, and $1 \%$ antibiotic/antimycotic solution. Medium was changed twice a week.

\section{Cell number per carrier}

At day 0 and 7 , fibrin gels $(n=3 /$ cell type/selected gel composition) were cut into four pieces, washed in TBSS for $5 \mathrm{~min}$ at RT, and incubated in TBBS containing $1 \%$ bovine pancreas trypsin (corresponding to around $90,000 \mathrm{U} / \mathrm{mL}$; Sigma) at $37^{\circ} \mathrm{C}$ (70-90 $\left.\mathrm{min}\right)$. Trypsin was then inactivated adding FBS. Cells were centrifuged $(500 \times g, 10 \mathrm{~min}, \mathrm{RT})$ and re-suspended in TBSS. Living cell number was evaluated with the trypan blue (Sigma) exclusion assay (each carriers counted six times), previously determined as an accurate method for absolute quantification of living and dead cells [19].

Cell morphology

At day 0 and 7 for C3H10T1/2 and at day $0,7,14$, and 21 for BMSCs, fibrin gels ( $n=3 /$ cell type/selected gel composition) were washed with TBSS and incubated in TBSS containing $10 \mu \mathrm{M}$ Calcein AM (Fluka; Buchs, Switzerland) for $3 \mathrm{~h}$ at $4{ }^{\circ} \mathrm{C}$ followed by $1 \mathrm{~h}$ at $37{ }^{\circ} \mathrm{C}$. Using a confocal laser scanning microscope (Carl Zeiss), cells were observed at the surface and inside the gel (100-150 $\mu \mathrm{m})$ at two random locations per gel.

Cell distribution

At day 3 and 10 for C3H10T1/2 and at day 3, 10, 17, and 24 for BMSCs, fibrin carriers $(n=3 /$ cell type/selected gel
Fig. 1 Effects of buffer solution composition on light transmission properties. Fibrin scaffolds were synthesized with different buffer solutions leading to different end concentrations of factor XIII (FXIII), calcium, and chloride ions. Light transmission properties are expressed as translucency relative to the 20.14.2.36.18 composition (dashed bars; for composition see Table 1). a Scaffolds were synthesized using $36 \mathrm{mM}$ chloride and different FXIII (6, 12 , and $18 \mathrm{U} / \mathrm{mL}$ ) and calcium $(2,9$, and $15 \mathrm{mM})$ concentrations. Values are mean $\pm \mathrm{SD} ; n=3$ scaffolds. b Gels were synthesized using $2 \mathrm{mM}$ calcium and different FXIII (12 and $18 \mathrm{U} / \mathrm{mL}$ ) and chloride $(36,100$, and $200 \mathrm{mM}$ ). Values are mean $\pm \mathrm{SD} ; n=3$ scaffolds
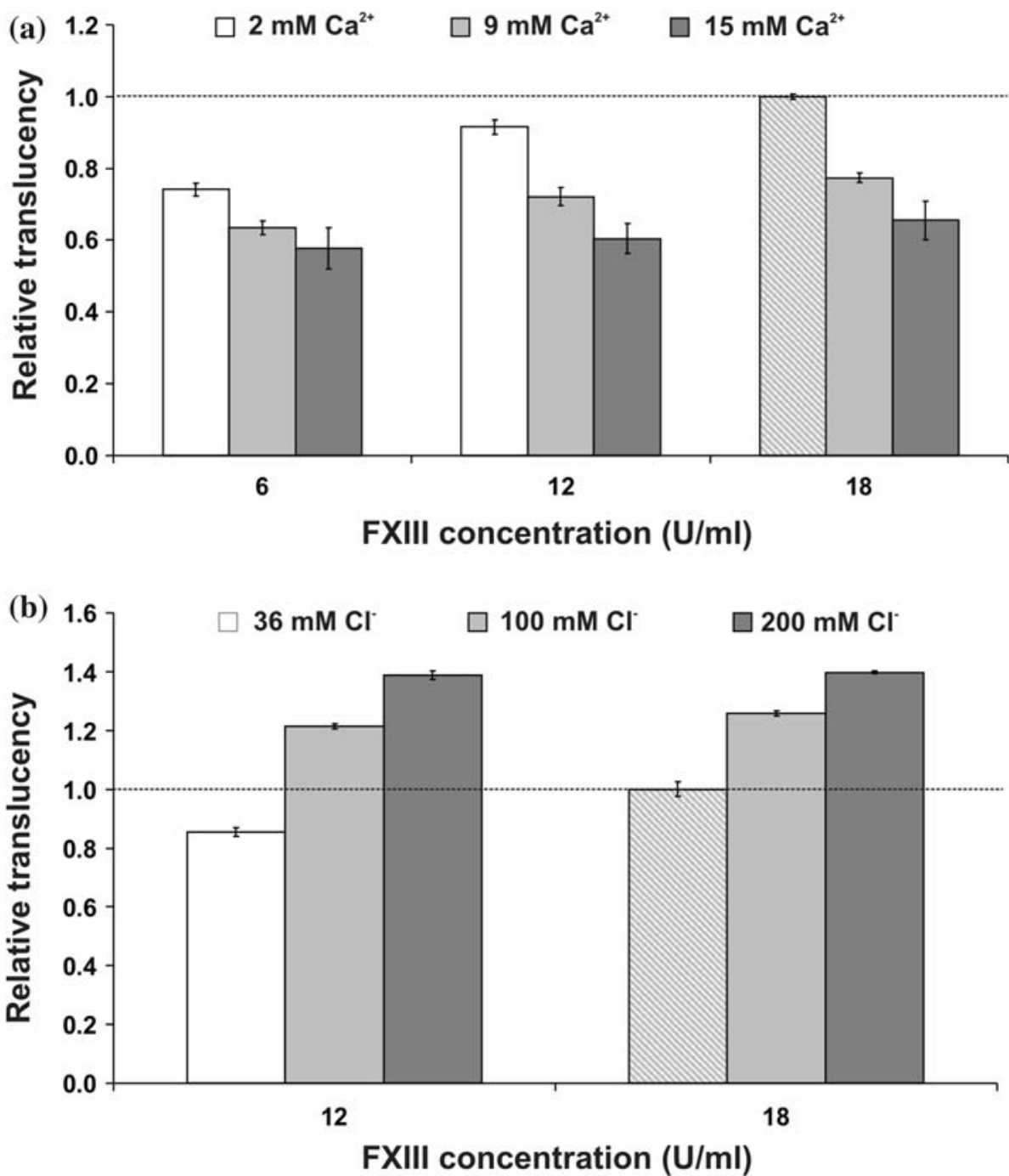
composition) were transferred into cryo-compound (Jung; Nussloch, Germany) and snap-frozen in liquid nitrogen. Cryo-sections of $12 \mu \mathrm{m}$ thick were cut axially in the middle of each carrier. Slides were then thawed and incubated in lactate dehydrogenase (LDH) staining solution (2 mM Gly-Gly buffer ( $\mathrm{pH} 8.0$ ), $40 \%$ Polypep, $60 \mathrm{mM}$ lactic acid, $1.75 \mathrm{mg} / \mathrm{mL} \beta$ nicotinamide adenine dinucleotide, and $3 \mathrm{mg} / \mathrm{mL}$ nitrotetrazolium blue chloride; all Sigma) for $3 \mathrm{~h}$ at $37{ }^{\circ} \mathrm{C}$ [20]. Slides were then rinsed once with $50{ }^{\circ} \mathrm{C}$ tap water, once with RT PBS, and fixed with $4 \%$ phosphate buffered formalin (10 min at RT). Slides were rinsed in PBS, counter-stained with propidium iodide $(1 \mu \mathrm{g} / \mu \mathrm{L}, 0.1 \%$ Triton $100 \times$, and $0.5 \mathrm{mg} / \mathrm{mL}$
RNaseA in PBS; all Sigma) for $5 \mathrm{~min}$ at RT, rinsed three times in PBS and mounted. Due to LDH stability [19], fibrin carriers were analyzed for LDH staining at day 3, 10, 17 , and 24 to ensure that only cells living at day $0,7,14$, and 21 were detected.

\section{Statistical analysis}

Quantitative data are expressed as mean \pm standard deviation (SD). Statistical analysis was performed using a general linear regression model. Statistical significance was assumed for $p<0.05$.
Fig. 2 Effects of buffer solution composition on mechanical properties. Stress relaxation reaction forces measured for the opaque (a) and translucent (b) fibrin scaffolds under unconfined compression at $2,4,6$, and $10 \%$ strain
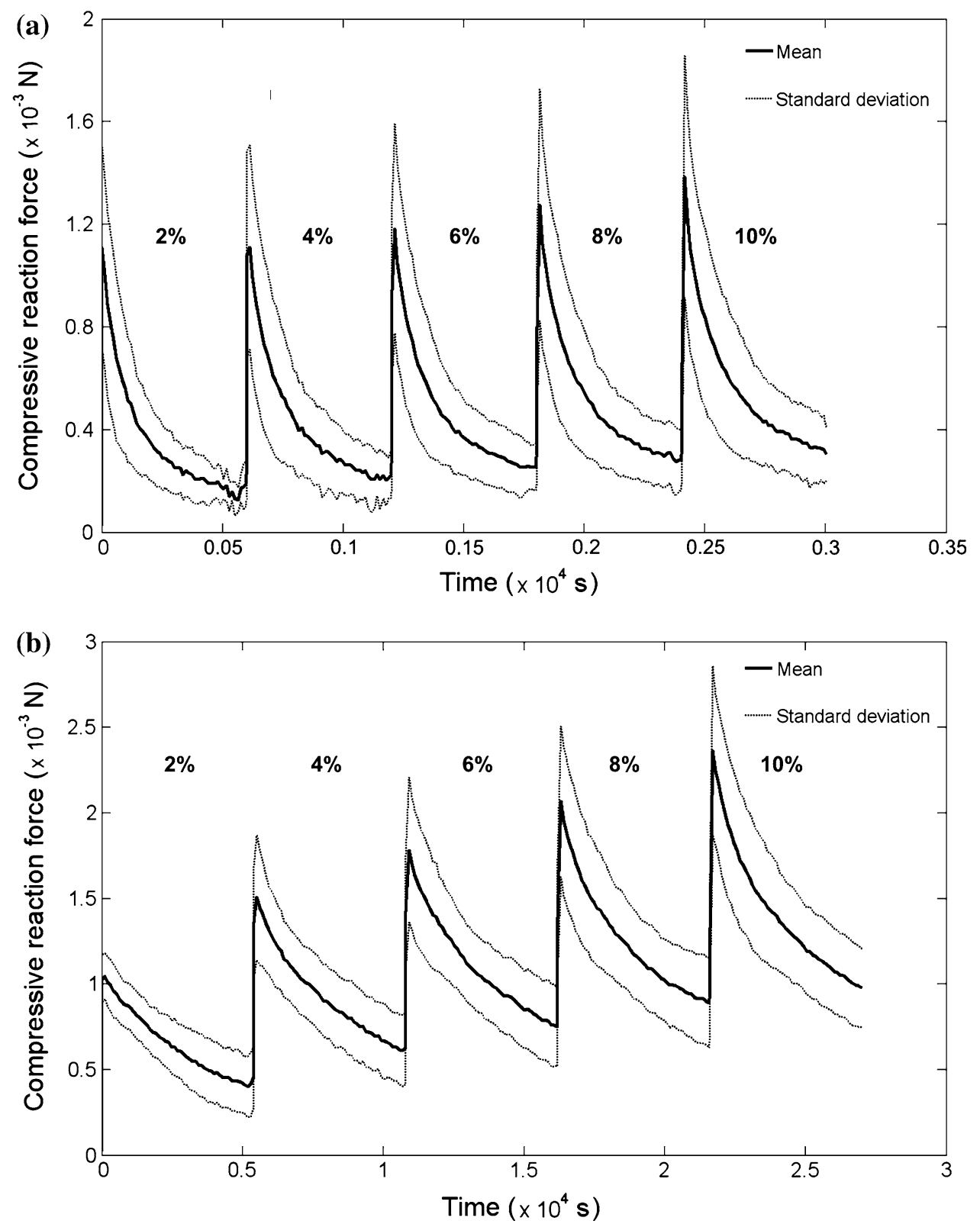


\section{Results}

Physical properties

\section{Effects on light transmission properties}

At constant chloride concentration (36 mM), increasing calcium content led to decreased light transmission (i.e., more turbid gels) whereas increasing FXIII had the opposite effect (Fig. 1a). Calcium, FXIII, and interaction between both components, were all determined to have a significant effect on light transmission properties ( $p=0.049, p<0.001$, and $p<0.001$, respectively). At a constant calcium concentration $(2 \mathrm{mM})$, increased chloride and FXIII contents both resulted in significant increased light transmission (i.e., less turbid gels) (Fig. 1b; $p<0.001$ and $p<0.001$, respectively). As for calcium and FXIII, interactions between chloride and FXIII had a significant effect $(p=0.001)$. From these results two fibrin compositions, one translucent and one opaque, were selected and were tested for mechanical properties and capability to support cell culture. Translucent gels (20.14.2.200.12) were composed of $20 \mathrm{mg} / \mathrm{mL}$ fibrinogen, $14 \mathrm{U} / \mathrm{mL}$ thrombin, $2 \mathrm{mM}$ calcium, $200 \mathrm{mM}$ chloride, and $12 \mathrm{U} / \mathrm{mL}$ FXIII. The opaque gels $(20.14 .15 .36 .6)$ contained $20 \mathrm{mg} / \mathrm{mL}$ fibrinogen, $14 \mathrm{U} / \mathrm{mL}$ thrombin, $15 \mathrm{mM}$ calcium, $36 \mathrm{mM}$ chloride, and $6 \mathrm{U} / \mathrm{mL}$ FXIII.

\section{Effects on mechanical properties}

For both translucent and opaque gels, reaction forces tended to increase with the strain level (Fig. 2). Such increases were generally more significant for the instantaneous than for the equilibrium forces and were also more pronounced for the translucent than for the opaque gels. Physical parameter values estimated for both gel types are summarized in Table 2. According to the experimental reaction forces, estimated equilibrium moduli $(E)$ were low, but stiffness of the translucent gels was about three times that of the opaque gels. Viscoelastic shear moduli $\left(G_{\mathrm{v}}\right)$ were similar for both gel types. However, while translucent gels $G_{\mathrm{v}}$ and $E$ values were comparable, $G_{\mathrm{v}}$ was about $200 \%$ higher than $E$ for the opaque gels. During the relaxation periods, equilibrium was nine times longer to reach for the translucent than for the opaque gels. Correspondingly, estimated relaxation time $(\lambda)$ and permeability $(\kappa)$ were, respectively,

Table 2 Scaffold small strain physical parameters estimated from the stress relaxation tests

\begin{tabular}{llllrl}
\hline Composition & Appearance & $E(\mathrm{~Pa})$ & $G_{\mathrm{v}}(\mathrm{Pa})$ & $\lambda(\mathrm{s})$ & $\kappa\left(\mathrm{mm}^{4} / \mathrm{Ns}\right)$ \\
\hline 20.14.15.36.6 & Opaque & 26 & 79 & 129 & 37 \\
20.14 .2 .200 .12 & Translucent & 76 & 78 & 2762 & 2 \\
\hline
\end{tabular}

one order of magnitude larger and smaller for the translucent gels, than for the opaque gels.

\section{Biological properties}

\section{Short-term culture}

C3H10T1/2 cells were able to proliferate in both compositions but opaque gels led to a larger increase in cell number after 1 week of culture (Fig. 3a; opaque: 312,700 $\pm 36,300$ cells/carrier; translucent: $178,600 \pm 2,200$ cells/carrier). Days of culture and the interaction between days of culture and gel composition were both found to have a significant effect on cell number $(p<0.001$ and $p<0.001$, respectively). Similar results were obtained with BMSCs ( $p<0.001$ and $p=0.016$, respectively), with a smaller increase in cell number for opaque gels at day 7 (Fig. 3b; opaque: $138,900 \pm 2,500$ cells/carrier; translucent: $123,400 \pm$ 10,800 cells/carrier). Both cell types were able to survive and spread on and inside both gel compositions as shown by calcein staining (Fig. 4). After 7 days of culture, cells displayed a fibroblast-like morphology and started to form a
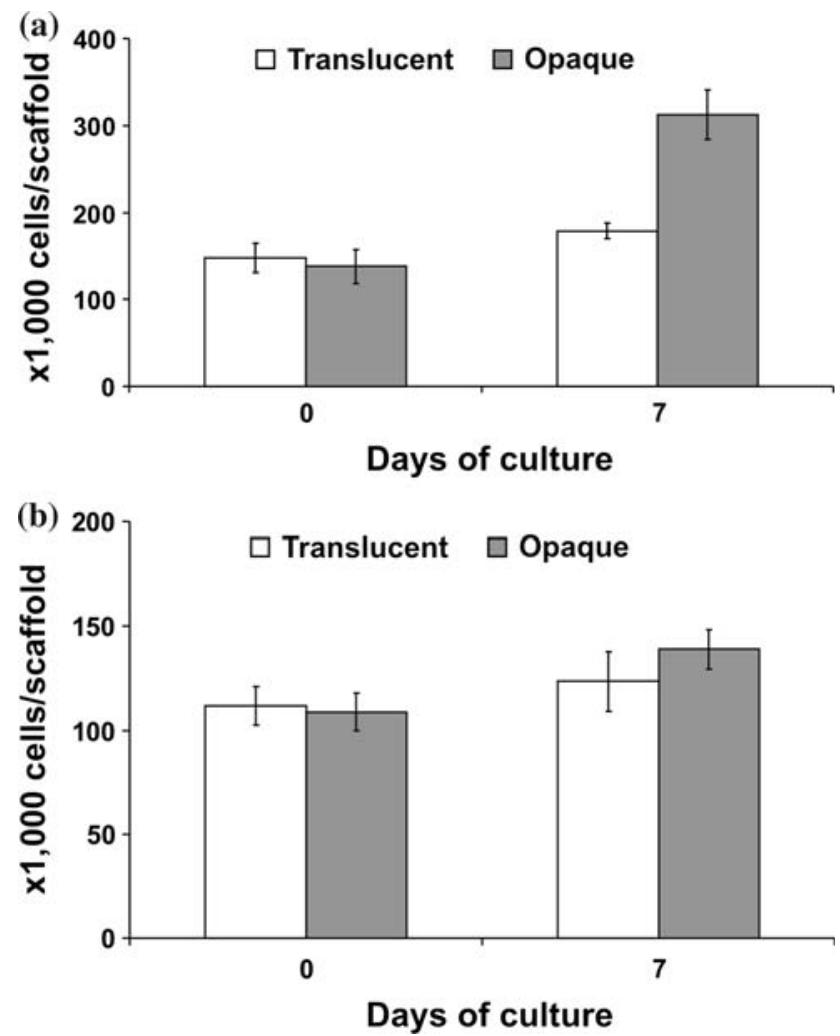

Fig. 3 Effects of buffer solution composition on cell number. Cells $(\mathrm{C} 3 \mathrm{H} 10 \mathrm{~T} 1 / 2$ (a) and BMSCs (b)) were seeded into translucent (white bars) and opaque (gray bars) fibrin scaffolds and cultured in medium containing 5\% FBS. At day 0 and day 7, cell number per scaffold was assessed by trypsin digestion and trypan blue staining. Values are mean $\pm \mathrm{SD} ; n=3$ scaffolds 
Fig. 4 Effects of buffer solution composition on cell morphology. C3H10T1/2 (a) and BMSCs (b) were seeded into translucent and opaque fibrin scaffolds and cultured in medium containing 5\% FBS. At day 0 and 7 , cell morphology was analyzed at the scaffold top surface and in a deeper layer (100-150 $\mu \mathrm{m}$ deep for translucent and 90-100 $\mu \mathrm{m}$ deep for opaque). Results presented are representative of three scaffolds. Scale bar $=5 \mu \mathrm{m}$
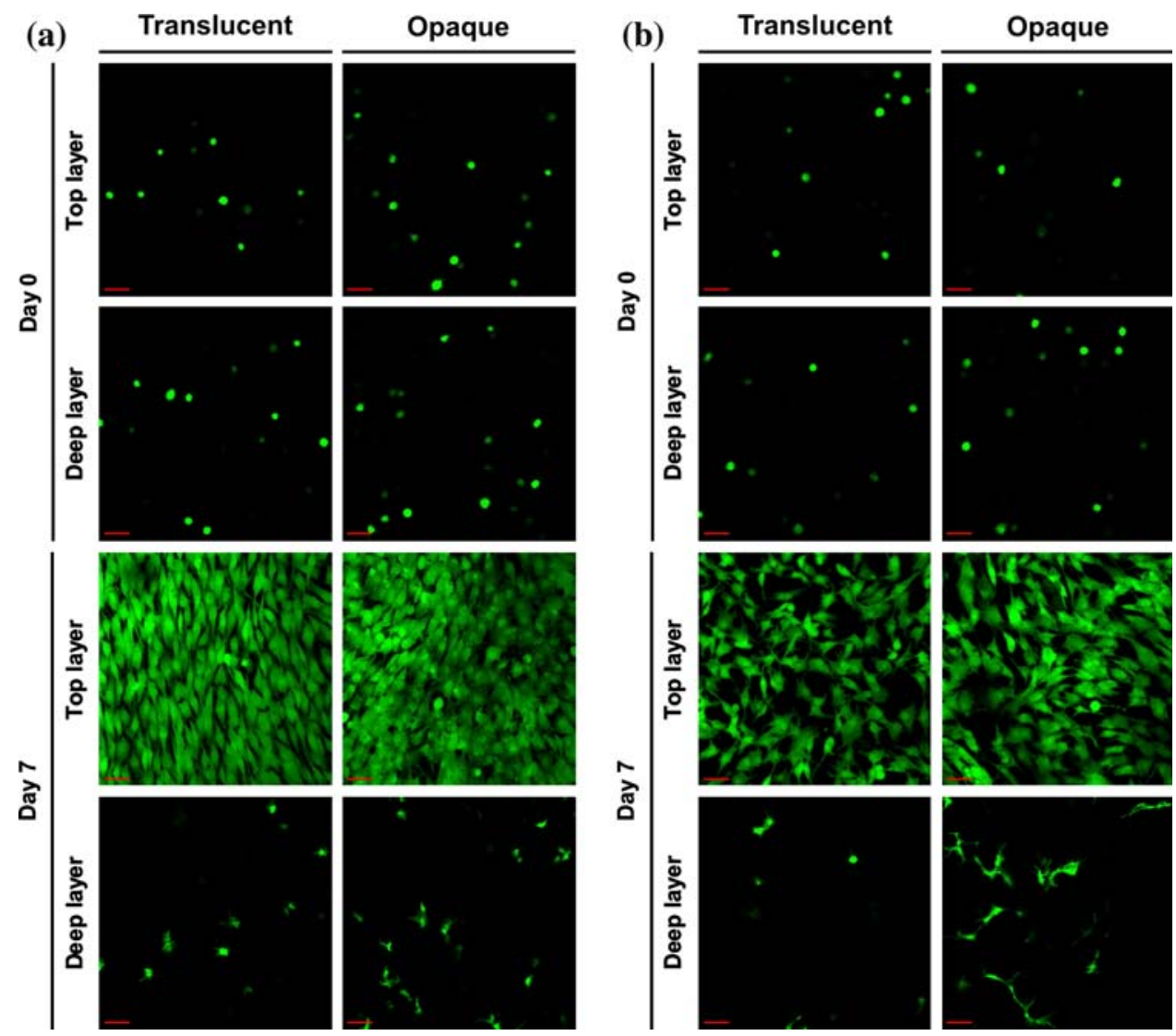

cell layer on top of the scaffolds. Cell density inside the scaffold was higher for the opaque gels than for translucent gels, with potential cell-cell contact only observed in the opaque gels (Fig. 4). LDH staining confirmed that both cell types formed a cell layer around the scaffolds and that cells proliferated more inside the opaque than inside the translucent gels (Fig. 5).

\section{Long-term culture}

Bone marrow-derived MSCs remained viable and displayed fibroblast-like morphology up to 21 days of culture in both gels (Fig. 6a). Cell density at day 21, however, was higher for opaque than for translucent gels. LDH staining showed that cell distribution remained homogenous throughout the scaffold with the formation of a dense multilayer of cells for both gel compositions (Fig. 6b). Similarly to day 10 , higher cell density was observed at day 17 and 24 for the opaque gels. But, starting at day 17, these gels showed a significant shrinkage.

\section{Discussion}

Opaque gels (obtained with high calcium and low chloride contents) displayed a pronounced fluid-like behavior, reflected by short relaxation time and reduced equilibrium stiffness (Fig. 2, Table 2). These findings agreed with several studies demonstrating increased opacity (corresponding to augmented fiber size [16]), but lowered rigidity, for gels with high calcium concentrations (up to $50 \mathrm{mM}$ ) [11, 21, 22]. Translucent gels (containing high chloride and low calcium concentrations) exhibited improved elastic properties (Fig. 2, Table 2). Experimental results are in accordance with previous studies presenting decreased turbidity in fibrin gels enriched with $\mathrm{NaCl}$ (up to $400 \mathrm{mM}$ ) [12, 23]. Note that the selected time for the relaxation period was taken at the very beginning of the plateau initially determined from the monitored forces. Therefore, due to the large time scale in Fig. 2b, no plateau can be distinguished, giving the impression that translucent gels did not reach equilibrium. Fibrin gel opacity and structure are known to be affected by calcium and chloride contents, but have also been linked to ionic strength of the gelling solution $[11,24]$. In the present study, the effects of calcium and chloride cannot be discriminated from those of ionic strength, and no conclusion can be drawn on the direct effects of calcium or chloride on fibrin structure.

At constant fibrinogen concentration, fibrin clots with increased apparent fiber thickness were experimentally shown to exhibit more fluid-like mechanical behaviors than clots with thin fibers [25]. Such phenomenon has been 
Fig. 5 Effects of buffer solution composition on cell distribution. C3H10T1/2 (a) and BMSCs (b) were seeded into translucent and opaque fibrin gels and cultured in medium containing 5\% FBS. At day 3 and 10 , cell distribution was analyzed with LDH staining after cryosectioning. Results presented are representative of three scaffolds. Scale bar $=2 \mathrm{~mm}$
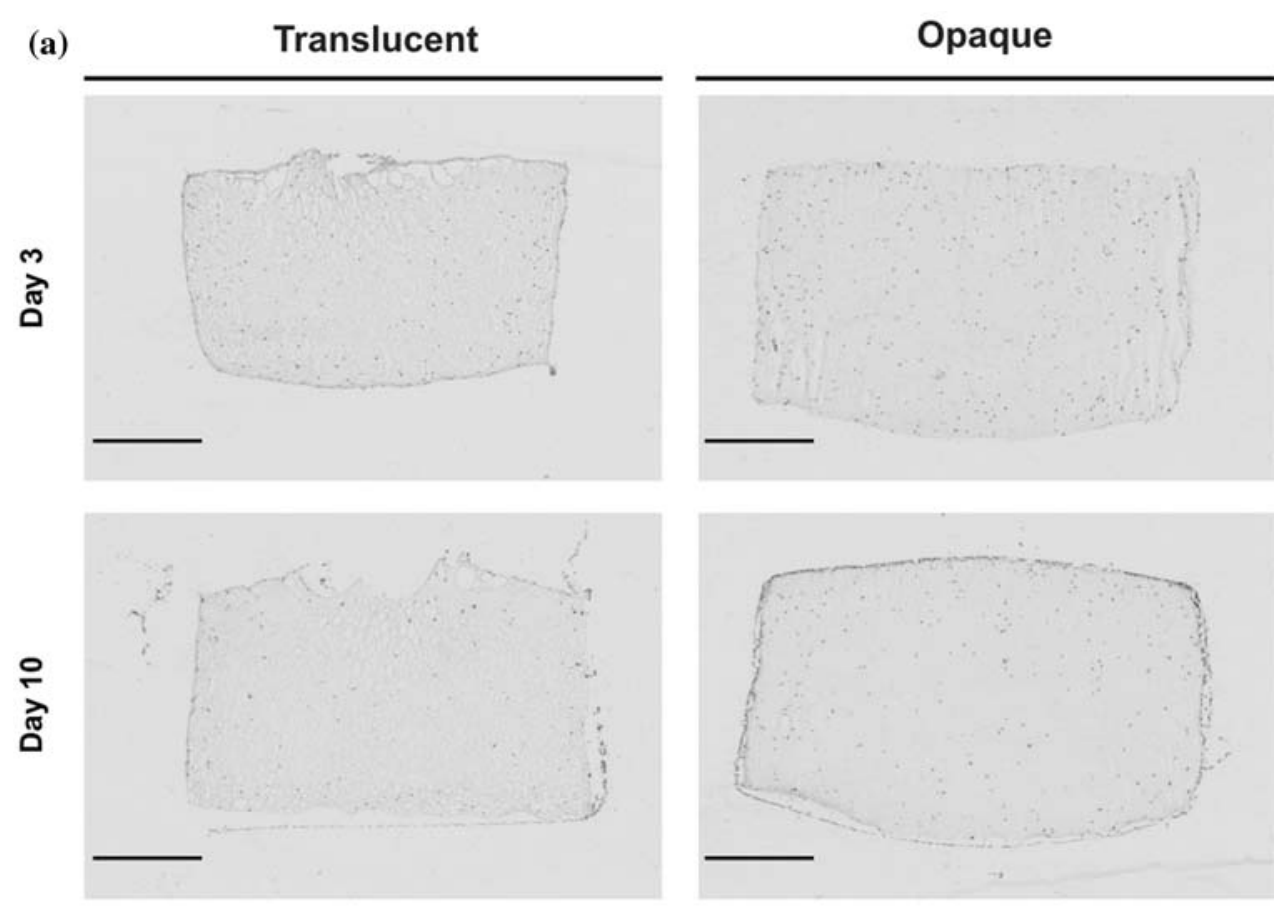

(b)

Translucent
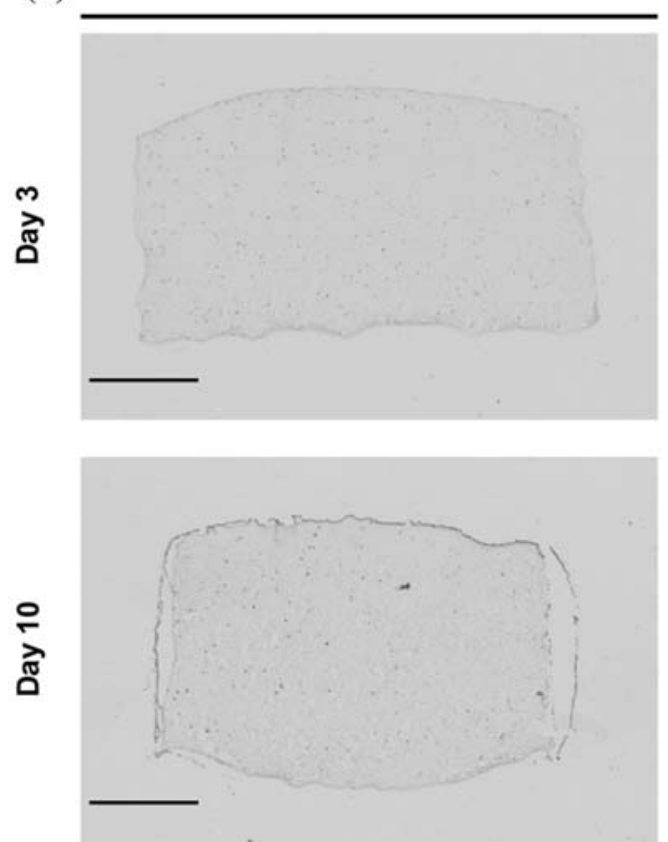
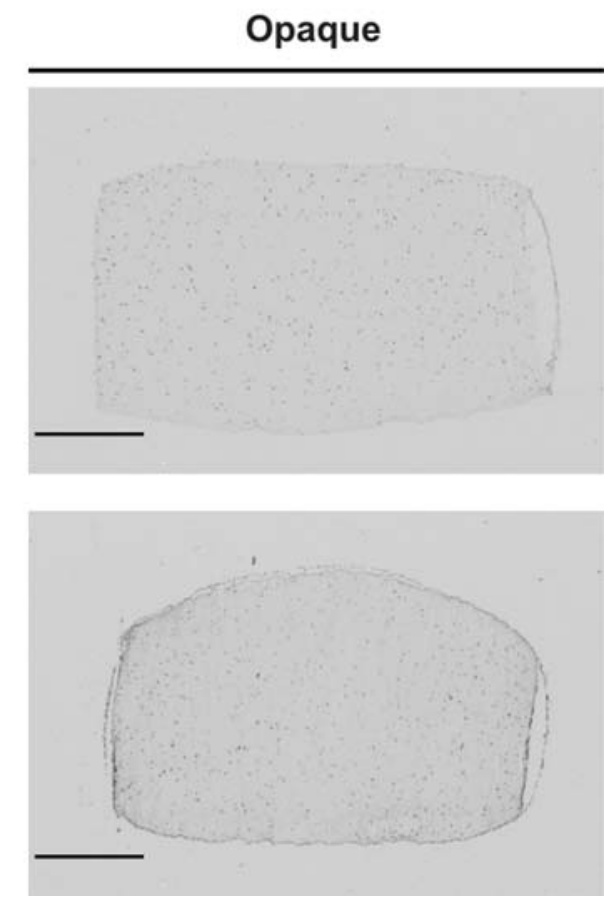

associated to possible slippage of the aggregated protofibrils [26, 27], which is in agreement with the low $E$ and $\lambda$ values estimated here for the tested opaque gels. Interestingly, $G_{\mathrm{v}}$ values found for the translucent and opaque samples were similar. This suggests that the instantaneous viscous response of the gels was rather controlled by fibrinogen and thrombin concentrations than by buffer solution composition. Actually, under short mechanical loading times, load-induced chain rearrangements may have little effects on fibrin response. Thus, $G_{\mathrm{v}}$ values should be more affected by the amount of monomer/ monomer associations (due to fibrinogen and thrombin), than by the structure of the polymer network, including lateral aggregations (modulated by buffer solution composition). Higher $\kappa$ values for the translucent than for the opaque gels are in agreement with the positive correlation 
Fig. 6 Effects of buffer solution composition on bovine BMSC morphology and distribution in long-term culture. BMSCs were seeded into translucent and opaque fibrin scaffolds and cultured in medium containing $5 \%$ FBS. a At day 14 and 21, cell morphology was analyzed at the scaffold top surface and in a deeper layer (100 $\mu \mathrm{m}$ deep). Results presented are representative of three scaffolds. Scale bar $=50 \mu \mathrm{m}$. b At day 17 and 24, cell distribution was analyzed with LDH staining after cryosectioning. Results presented are representative of three scaffolds. Scale bar $=2 \mathrm{~mm}$
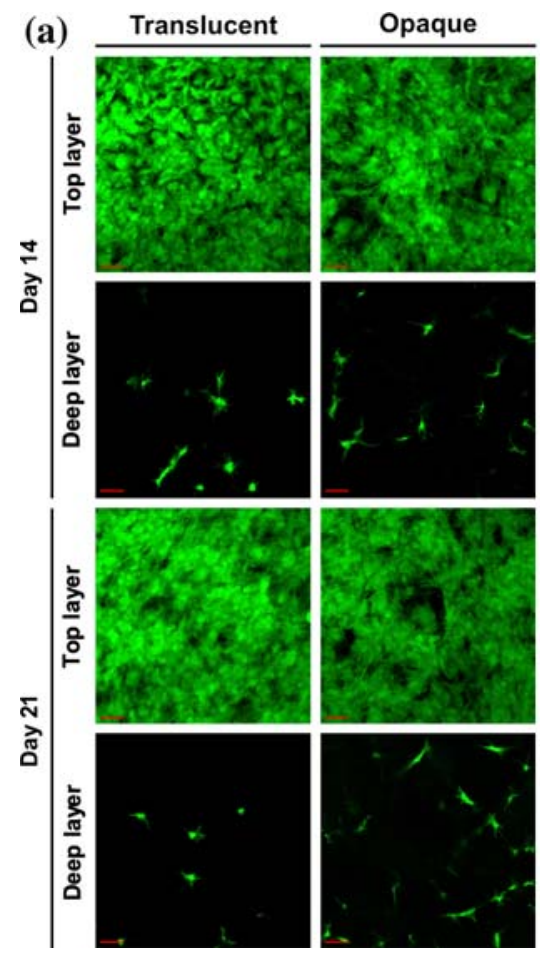

\section{(b)}

Translucent
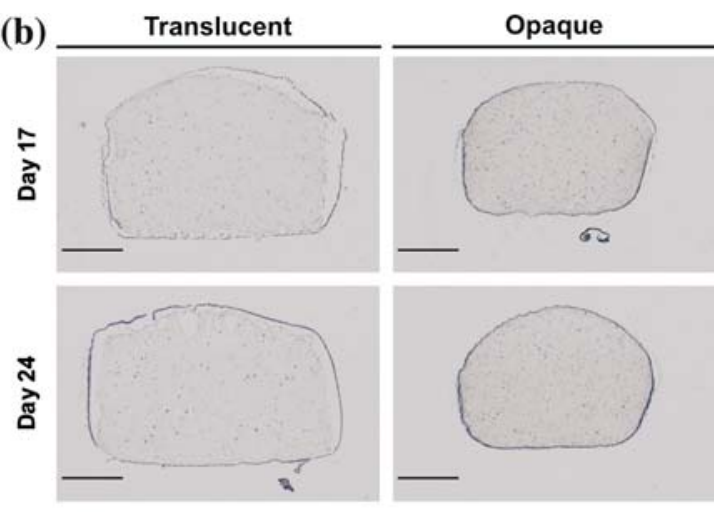

reported between fibrin turbidity and gel porosity/permeability [28]. In turn, this porosity/permeability was suggested to predominantly depend on the arrangement of the fibers [29]. Moreover, FXIII content, larger for the translucent than for the opaque gels, could also contribute to the different permeability values estimated in both gels.

Mouse mesenchymal cells (C3H10T1/2) and bovine bone marrow-derived MSCs (BMSCs) seeded into the gels displayed a fibroblastic-like morphology with several cellular processes even after 3 weeks of culture (Fig. 6), therefore establishing the non-toxicity of the modified fibrin gels (and confirmed by trypan blue exclusion assay). Both cell types were able to proliferate in both gel compositions, but to a larger extent in the opaque gels (Figs. 4, 6). Same results were observed by Nehls et al. with bovine endothelial cells [23]. Using different $\mathrm{pH}$ to modulate fibrin structure, they showed better cell migration and proliferation in turbid than in transparent fibrin gels. This reduced cell proliferation might be caused by difficulty for the cells to degrade local matrix, impeding cell migration and proliferation through the gel. In turn, resistance to fibrinolysis may be due to increased FXIII content in the translucent gels $[15,30,31]$ but also to the gel structure itself, as thin fibers have been showed to degrade at a slower rate than large fibers [32]. However, aprotinin, a fibrinolysis inhibitor, was added in the culture medium in order to impede the degradation of the gel over time. Hence, greater matrix degradation in the opaque gels is unlikely. Decrease of aprotinin activity during culture or a poor diffusion of aprotinin inside the gels, however, cannot be ruled out. The present study, therefore, cannot discriminate between the effects of gel structure and the effects of fibrinolysis resistance on cell behavior. Fibrin degradation may be evaluated adding fluorescent fibrinogen monomers in the scaffold and measuring their release during cell culture [33]. Using such a technique it may be possible to determine whether there is a difference in fibrinolysis resistance between opaque and translucent gels.

Another possibility to explain the different cell behavior is the modulation of cell proliferation by the mechanical properties of the matrix itself. Matrix elasticity, indeed, has been showed to modulate morphology, proliferation, and differentiation profile of human BMSCs [34, 35]. The translucent gels used in this study displayed a stronger elastic behavior than the opaque gels (Table 2), potentially influencing cell proliferation. But the development of equivalent cell layers at scaffold surface for both gel compositions (Fig. 4) suggests that, at least in 2D, there was no influence of matrix elasticity on cell proliferation.

During the entire period of culture (3 weeks) the opaque gels supported a better proliferation of BMSCs. These gels, however, started to shrink as early as 17 days of culture (Fig. 6). This contraction might be imputable to enhanced matrix degradation caused by higher cell number and/or lower resistance to fibrinolysis. However, as aforementioned, aprotinin was added to the cell culture medium to impede fibrin degradation. Thus, shrinkage is more likely a result of weaker resistance of the matrix to the traction applied by the cells as they form a layer around the scaffold. 
From these results, opaque fibrin gels appeared to be better for cell proliferation. However, they might not be the more appropriate for tissue engineering. Indeed, according to Ahmed et al., fibrin hydrogels as cell scaffold for tissue engineering have three major disadvantages: matrix shrinkage, low mechanical stiffness, and rapid degradation before proper tissue formation [2]. The translucent gels, though not supporting cell proliferation, were able to maintain the initial cell number and to sustain cell survival up to 3 weeks of culture without noticeable carrier shrinkage. Moreover, they present an improved mechanical stiffness and, probably, a decreased sensitivity to fibrinolysis. They can, therefore, represent better candidates as cell scaffold for tissue engineering applications.

The present study only addressed the effects of fibrin composition on cell survival and proliferation while cell differentiation is as important for tissue engineering applications. Scaffolds leading to better cell proliferation are not necessarily more appropriate for cell differentiation as illustrated by the study of Catelas et al. [8]. They showed that high-fibrinogen content, though lowering cell proliferation rates, improved osteogenic differentiation of human BMSCs. The effects of physical changes induced by different buffer compositions, therefore, should also be tested on the differentiation potential of BMSCs to really conclude on the interest of the translucent fibrin scaffolds presented here as cell carriers for tissue engineering. Moreover, other factors, not studied here, can play a role in survival and/or proliferation of cells, such as the species (rat BMSCs more sensitive to plating density than human BMSCs [36]), the cell culture medium (adding dexamethasone rescues bovine BMSCs seeded into agarose gels [37]) or the cell type (bovine chondrocytes can proliferate in transparent fibrin gels [5]).

These results demonstrated that, not only fibrinogen and thrombin, but also dilution buffers can significantly affect fibrin mechanical properties and the behavior of seeded cells. Modulating buffer composition can, therefore, constitutes an additional tool to tailor fibrin scaffolds with mechanical and biological properties appropriate for tissue engineering applications, such as bone or cartilage regeneration.

Acknowledgements We would like to thank Baxter Biosurgery (Vienna, Austria) for providing fibrin components and related solutions, and Dr A. Goessl for his help with the manuscript. We also thank M. van der Werf and S. Zeiter for providing the bovine BMSCs and P. Lezuo for his work on relaxation tests.

Open Access This article is distributed under the terms of the Creative Commons Attribution Noncommercial License which permits any noncommercial use, distribution, and reproduction in any medium, provided the original author(s) and source are credited.

\section{References}

1. Mosesson MW, Siebenlist KR, Meh DA (2001) Ann N Y Acad Sci 936:11

2. Ahmed TA, Dare EV, Hincke M (2008) Tissue Eng Part B Rev 14:199

3. Cox S, Cole M, Tawil B (2004) Tissue Eng 10:942

4. Rowe SL, Lee S, Stegemann JP (2007) Acta Biomater 3:59

5. Eyrich D, Brandl F, Appel B, Wiese H, Maier G, Wenzel M et al (2007) Biomaterials 28:55

6. Kirilak Y, Pavlos NJ, Willers CR, Han R, Feng H, Xu J et al (2006) Int J Mol Med 17:551

7. Bensaid W, Oudina K, Viateau V, Potier E, Bousson V, Blanchat C et al (2005) Tissue Eng 11:814

8. Catelas I, Sese N, Wu BM, Dunn JC, Helgerson S, Tawil B (2006) Tissue Eng 12:2385

9. Ho W, Tawil B, Dunn JC, Wu BM (2006) Tissue Eng 12:1587

10. Tredree R, Beierlein W, Debrix I, Eisert A, Goffredo F, Gomez de Salazar E et al (2006) EJHP Sci 12:3

11. Carr ME Jr, Gabriel DA, McDonagh J (1986) Biochem J 239:513

12. Di Stasio E, Nagaswami C, Weisel JW, Di CE (1998) Biophys J 75:1973

13. Hantgan RR, Hermans J (1979) J Biol Chem 254:11272

14. Ryan EA, Mockros LF, Stern AM, Lorand L (1999) Biophys J $77: 2827$

15. Urech L, Bittermann AG, Hubbell JA, Hall H (2005) Biomaterials $26: 1369$

16. Carr ME Jr, Hermans J (1978) Macromolecules 11:46

17. Weisel JW, Nagaswami C (1992) Biophys J 63:111

18. Noailly J, Van Oosterwyck H, Wilson W, Quinn TM, Ito K (2008) J Biomech 41:3265

19. Gantenbein-Ritter B, Potier E, Zeiter S, van der Werf M, Sprecher CM, Ito K (2008) Tissue Eng Part C Methods 14:353

20. Stoddart MJ, Furlong PI, Simpson A, Davies CM, Richards RG (2006) Eur Cell Mater 12:16

21. Ryan EA, Mockros LF, Weisel JW, Lorand L (1999) Biophys J 77:2813

22. Yao L, Swartz DD, Gugino SF, Russell JA, Andreadis ST (2005) Tissue Eng 11:991

23. Nehls V, Herrmann R (1996) Microvasc Res 51:347

24. Blomback B, Okada M (1982) Thromb Res 25:51

25. Roberts WW, Kramer O, Rosser RW, Nestler FH, Ferry JD (1974) Biophys Chem 1:152

26. Gerth C, Roberts WW, Ferry JD (1974) Biophys Chem 2:208

27. Weisel JW (2004) Biophys Chem 112:267

28. Okada M, Blomback B (1983) Ann N Y Acad Sci 408:233

29. van Gelder JM, Nair CH, Dhall DP (1995) Blood Coagul Fibrinolysis 6:293

30. Edwards MW, de Bang E, Strout J, Bishop PD (1993) Fibrinolysis 7:211

31. Gladner JA, Nossal R (1983) Thromb Res 30:273

32. Gabriel DA, Muga K, Boothroyd EM (1992) J Biol Chem 267:24259

33. Willerth SM, Arendas KJ, Gottlieb DI, Sakiyama-Elbert SE (2006) Biomaterials 27:5990

34. Engler AJ, Sen S, Sweeney HL, Discher DE (2006) Cell 126:677

35. Winer JP, Janmey PA, McCormick ME, Funaki M (2009) Tissue Eng A 15:147

36. Javazon EH, Colter DC, Schwarz EJ, Prockop DJ (2001) Stem Cells 19:219

37. Mauck RL, Yuan X, Tuan RS (2006) Osteoarthritis Cartilage 14:179 